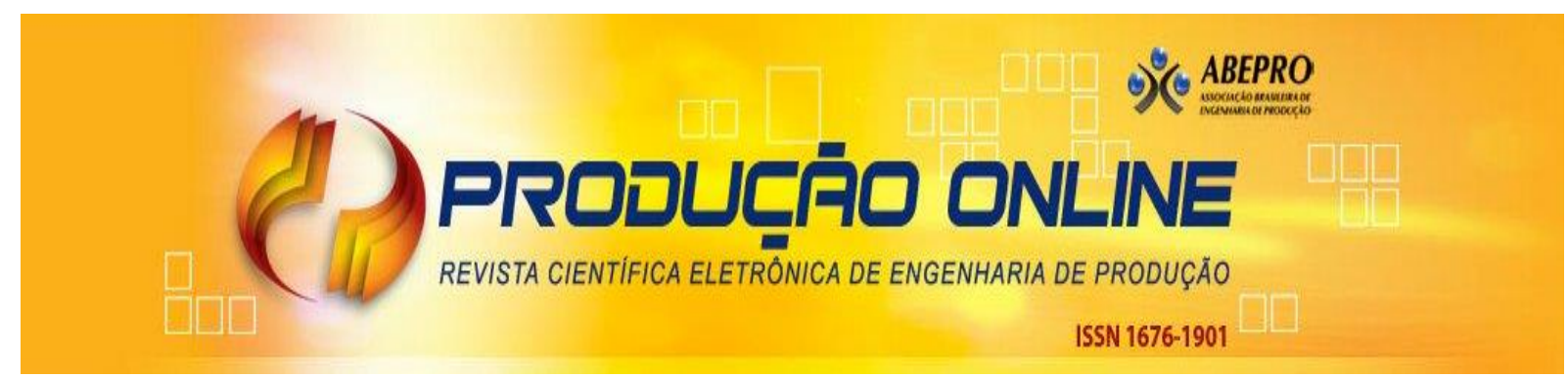

\title{
PROPOSTA DE MELHORIA POR MEIO DE KPI EM UMA EMPRESA DE MOVELARIA COM FORNECEDORES NO EXTERIOR
}

\section{PROPOSAL FOR IMPROVEMENT BY KPI IN A FURNITURE COMPANY WITH SUPPLIERS ABROAD}

\author{
Paulo Henrique Carneiro de Andrade* E-mail: phcandrade@gmail.com \\ * IBMEC-MG, Belo Horizonte, MG
}

\begin{abstract}
Resumo: O objetivo deste trabalho foi estabelecer mostrar a importância na utilização de indicadores de desempenho. $O$ presente trabalho foi realizado em uma empresa de movelaria que produz estofados, Rostagno, localizada em Turim - Itália. Este artigo mostrou a importância dos indicadores de desempenho na gestão da logística e no planejamento estratégico de empresa, apontando como gerir seus fornecedores, utilizando ferramentas e propondo indicadores e melhorias, demonstrando como tal implica maior eficiência e ganho de resultados. Para compreender claramente o proposto, foi definido o conceito de logística, estoque, indicadores de desempenho (KPI), análise das vantagens e desvantagens de manter um estoque e como isso interfere no resultado da empresa. Foram analisados fornecedores da China, Polônia e Romênia. Deste modo, foi possível propor quais os pontos necessários para se avaliar o fornecedor e estabelecer critérios para verificação do cumprimento dos mesmos quanto aos objetivos estabelecidos. Diante do que foi apresentado, conclui-se que os indicadores proporcionam um maior controle em relação a escolha do fornecedor, considerando custo do transporte e mão de obra, resultando em vantagem competitiva para a Rostagno e também oportunidades de melhoria.
\end{abstract}

Palavras-chave: Estoque. KPI. Logística. Planejamento Estratégico. Movelaria.

\begin{abstract}
The objective of this work was to establish the importance of using KPI's. The present work was carried out in an italian furniture company. This article showed the importance of performance indicators in logistics management and in company strategic planning, pointing out how to manage its suppliers, using tools and proposing indicators and improvements, demonstrating how this implies greater efficiency and results gain. To clearly understand the proposal, we defined the concept of logistics, inventory, performance indicators, analysis of the advantages and disadvantages of maintaining a stock and how this interferes with the company's results. Suppliers from China, Poland and Romania were analyzed. In this way, it was possible to propose the necessary points to evaluate the supplier and to establish criteria for verifying compliance with the established objectives. In view of the above, it is concluded that the indicators provide greater control over the choice of supplier, resulting in a competitive advantage and also opportunities for improvement.
\end{abstract}

Keywords: Inventory. KPI. Logistics. Strategic Planning. Furniture.

\section{INTRODUÇÃO}

Consumidores, mundialmente, valorizam produtos "Made in Italy", sinônimos 
de prestígio, alta qualidade e design exclusivo. Não é diferente com o mobiliário da Rostagno. Entretanto, a produção realizada na Itália não é competitiva, o custo da mão de obra é mais caro que em outros países da união europeia, como Romênia e Polônia, sem falar na produção realizada na China.

A Rostagno não possui fábrica no exterior, utiliza-se da prática de outsourcing para a produção, mantendo o desenvolvimento dos seus projetos na Itália. As causas para essa prática são inúmeras. Para entender um dos motivos que fizeram várias empresas italianas procurarem novos fornecedores estão: custos do trabalho já citados; impostos que aumentam o custo direto e, em seguida, talvez o fator que mais impacta na competitividade, a lei trabalhista, de 1970, desatualizada e não mais aplicável atualmente.

A atual globalização da economia e a crescente competição de mercado marcam a era da informação, em que o aperfeiçoamento e inovação dos processos e serviços se conectam com a boa gestão e com a correta tomada de decisão para garantir sobrevivência das empresas (CANHADAS, 2010).

Então, para se manter competitivo no mercado mundial, com grande demanda para produtos italianos, a Rostagno propõe vender o produto com o Design italiano, mas "Made in China". Sendo a gestão produtiva dividida dessa maneira: o trabalho de design é realizado em Turim pelos próprios funcionários; após, encaminha-se para fabricação na China. A qualidade é controlada com envio de responsáveis à China para acompanhar a produção, onde o sistema organizacional para exportação dos produtos é muito eficiente. Após a produção realizada na fábrica chinesa, o envio é efetuado diretamente ao cliente final.

Considerando esse cenário e a crescente exigência dos clientes, as empresas não podem apenas vender um produto, é preciso transmitir uma proposta de valor alinhada a uma experiência positiva, onde pequenos detalhes diferenciam um produto considerado exclusivo daqueles comuns. Neste aspecto, a Rostagno oferece um serviço de projetação, quando o cliente pode visualizar como vai ficar o móvel desejado, uma verdadeira revolução neste mercado, alterando aquela visão de ser apenas um ponto de venda de móveis comuns e se transformando em um vendedor de projetos exclusivos.

Neste contexto, procurar uma vantagem competitiva é fundamental para sobrevivência da empresa. "Trata-se da vantagem competitiva. Procura identificar 
propriedades específicas e combinações individuais de produtos e mercados que dão à empresa uma forte posição concorrencial”. (Ansoff, 1965, p. 93).

"Vantagem competitiva surge, fundamentalmente, do valor que uma empresa é capaz de criar para seus compradores, valor este que excede o custo da empresa em criá-lo. Valor é o que os compradores estão dispostos a pagar, e valor superior provém da oferta de preços inferiores aos dos concorrentes para benefícios equivalentes ou o fornecimento de benefícios únicos que mais do que compensam um preço superior. Existem dois tipos básicos de vantagem competitiva: liderança de custos e diferenciação". (Porter, 1985, p. 3,).

Assim, a necessidade de desenvolver indicadores capazes de efetivamente medir o desempenho das atividades realizadas pela empresa de modo a propor qual melhor opção para a produção no exterior, comparando os fornecedores contratados recentemente pela empresa.

\section{REFERENCIAL TEÓRICO}

\subsection{Planejamento Estratégico}

Segundo Kotler (1992), "o planejamento estratégico se trata de uma metodologia gerencial que permite estabelecer a direção a ser seguida pela organização, visando uma maior interação com o ambiente", Oliveira (1991, p. 62), acrescenta que o "planejamento estratégico é um processo gerencial que possibilita ao executivo estabelecer o rumo a ser seguido pela empresa, com vistas a obter um nível de otimização na relação da empresa com o seu ambiente. " Além disso, o planejamento estratégico deve estar alinhado aos propósitos da empresa, conforme GAJ (2002, p.126) “o planejamento estratégico do negocio de uma empresa deve em primeiro lugar se orientar pela estratégia coorporativa, que é normalmente baseada na missão e na visão da empresa, assim esses dois itens se tornam os indispensáveis para sua elaboração, no entanto há outras etapas também importantes na elaboração de um plano estratégico de negócio."

De acordo com Chiavenato e Sapiro (2009), planejamento estratégico é um processo contínuo nas organizações, com uma percepção do futuro para tomada de decisões atuais que podem afetar os objetivos traçados, fazendo com que a 
organização reavalie as suas atividades e acompanhe os resultados e confronte com as expectativas.

Para que ocorra a execução da estratégia é necessário que todas as pessoas que façam parte da organização estejam comprometidas, desde o presidente até a base da estrutura organizacional, fazendo com que haja intenso engajamento, consenso, conhecimentos, informação, estejam motivados, compromissados e liderança por parte de toda a cúpula da empresa (CHIAVENATO e SAPIRO, 2009).

\subsection{Logística}

Segundo Ballou (1998), "a logística empresarial estuda como a administração pode prover melhor nível de rentabilidade nos serviços de distribuição aos clientes e consumidores, através de planejamento, organização e controle efetivo para as atividades de movimentação e armazenagem que visam facilitar o fluxo de produtos", seguindo esta linha de definição, Pires (1998), define " a logística engloba o processo de planejamento, implementação e controle da eficiência, custos efetivos de fluxos e estoque de matéria-prima, estoque circulante, mercadorias acabadas e informações relacionadas do ponto de origem ao ponto de consumo com a finalidade de atender aos requisitos do cliente". Trazendo para um conceito sobre logística moderna, Novaes (2001) comenta que "a logística moderna coliga todos os elementos do processo, prazos, integração de setores da empresa e formação de parcerias com fornecedores e clientes para satisfazer as necessidades e preferências dos consumidores finais."

De acordo com Duarte (2016, p. 65), logística é a "ciência que estuda a ordem do dinheiro dento da cadeia de abastecimento (Supply Chain), a fim de garantir o melhor custo-benefício operacional, com qualidade, pontualidade, assertividade, acuracidade, controle e segurança".

Segundo Dornier et al. (2012), a operação logística se tornou um facilitador crítico para a integração das estratégias globais desenvolvidas pelas empresas. Ao integrar a logística ao processo decisório, as empresas podem obter uma vantagem competitiva por meio da racionalização dos recursos necessários para realizarem esta tarefa. O marketing capta as necessidades dos clientes, mas a logística é a responsável por entregar ao cliente final. 


\subsection{Key Performance Indicator}

A sigla KPI é originada da língua inglesa, e representa a junção das 3 primeiras letras das palavras Key Performance Indicator, que pode ser entendido em português como indicador chave de desempenho. De acordo com Parmenter (2007), os KPIs podem ser representados pela combinação de um ou mais indicadores, e representam um conjunto de medidas focadas nos aspectos mais críticos para o desempenho satisfatório e atingimento dos objetivos organizacionais.

Para a Fundação Nacional da Qualidade - Critérios de Excelência (2008), os indicadores de desempenho compreendem os dados que quantificam as entradas (recursos ou insumos), ao processo, as saídas (produtos), o desempenho de fornecedores e a satisfação das partes interessadas. Outra definição é dada pela FNQ/CE, Resultados (2008, p. 7), "um indicador de desempenho é um dado numérico a que se atribui uma meta e que é trazido, periodicamente, à atenção dos gestores de uma organização".

Para Gibbon (1990) os KPI (Key performance indicator) são valores mensuráveis que demonstram a eficiência da companhia em alcançar os objetivos. As organizações usam vários níveis de KPI para avaliar o sucesso de cada meta. Sendo os KPIs de nível maior usado para o desempenho geral da empresa, enquanto de nível menor para processos em departamentos, como vendas, marketing ou call center.

Como definição, um indicador é uma ferramenta que permite a obtenção de informações sobre uma dada realidade, tendo como característica principal poder sintetizar diversas informações, retendo apenas o significado essencial dos aspectos analisados (MITCHELL, 2004).

Partindo da afirmação de Juran e Gryna (1998), sem controle não há administração e sem medição não há controle, pode-se observar o grau de importância da medição de desempenho como atividade de verificação ou compreensão da realidade organizacional, tendo em vista os objetivos estratégicos da mesma.

O conceito do indicador de desempenho está associado a um modelo e uma variável aleatória em função do tempo. Portanto, definem indicadores como formas de representação quantificável de características (atributos ou requisitos) de produtos (bens + serviços) e processos (conjunto de causas e condições que transforma 
recursos em produtos) utilizados para acompanhar e melhorar os resultados ao longo do tempo (ZELTZER, 2005).

Os principais requisitos para gerar um indicador são: grau de importância, simplicidade e clareza, baixo custo de obtenção, representativo e/ou abrangente, estável e durável, rastreável e acessível, confiável e coerente, comparável; sistema de informação (identificar fonte de dados, eliminar indicadores inviáveis), medição e análise de dados e resultado (coletar, processar e analisar os dados e resultados), uso dos dados e resultados (tomar decisões com base nas análises), avaliação e melhoria (avaliar o uso dos indicadores, aprimorar o sistema dos indicadores) (ZELTZER, 2005).

\subsection{Estoque}

Estoque é a acumulação armazenada de recursos materiais em um sistema de transformação. O estoque também é usado para descrever qualquer recurso armazenado. Todavia apesar desses recursos de transformação serem tecnicamente considerado como estoque, não são obtidos sempre que um consumidor faz uma solicitação, não são o que normalmente se dizem como termo estoque. (SLACK, 2009).

Segundo Ballou (1998, p. 204) o controle de estoque é a parte vital do composto logístico, pois estes podem absorver de 25 a 40\% dos custos totais da produção, representando uma porção substancial do capital da empresa. Ainda segundo o autor, os estoques possuem uma série de objetivos, como: - Melhorar o nível de serviço; Incentivam economias na produção; - Permitem economia de escala nas compras e no transporte; - Agem como proteção contra aumentos de preços; - Protegem a empresa de incertezas na demanda e no tempo de ressuprimento; - Servem como segurança contra contingências. Portanto, um bom controle de estoque passa primeiramente pelo planejamento desse estoque

\subsection{Controle do estoque}

De acordo com Moreira (2008), há dois pontos principais segundo os quais a gestão de estoques adquire grande importância e merece cuidados especiais: o operacional e o financeiro. 
Vendrame (2008), conceitua que o objetivo básico do controle de estoque é evitar a falta de material sem que esta diligência resulte em estoque excessivos às reais necessidades da empresa. $O$ equilíbrio entre a demanda e a obtenção de material é o principal objetivo do controle do estoque, para garantir uma gestão eficiente e eficaz.

Conforme Beulke e Bertó (2001), os estoques das empresas industriais costumam se apresentar sob três formas:

1. Materiais adquiridos e ainda não utilizados;

2. Produtos em fase de elaboração;

3. Produtos prontos.

\section{METODOLOGIA}

Para o inicio do trabalho, foi necessário um mapeamento dos processos na empresa desde a entrada do cliente onde ele faz o pedido até a entrega final do produto, que segundo (BARBROW; HARTLINE, 2015) "mapeamento de processos vem ao encontro da identificação dos principais passos e decisões em um fluxo de trabalho de rotina de forma visual.Também controla o fluxo de informações, materiais e documentos envolvidos no processo e esclarece tarefas, decisões e ações que são necessárias em determinados pontos no tempo"

Para o desenvolvimento do estudo foi utilizado um questionário com o responsável pela operação da empresa, entrevistas com os proprietários e com a área comercial da empresa encarregada do contato com os fornecedores, como forma de coleta de dados. Segundo Parasuraman (1991), "um questionário é tão somente um conjunto de questões, feito para gerar os dados necessários para se atingir os objetivos do projeto. "Por fim os contratos foram analisados e indetificou-se oportunidades de ganho quando comparados.

O trabalho foi dividido em pesquisa bibliográfica e estudo de caso prático. $\mathrm{O}$ estudo consistiu em um primeiro momento na coleta e organização dos dados. Após esta etapa, iniciou-se a interpretação e analise de dados coletados com a própria empresa e com seus fornecedores. Para a definição do objeto de estudo, algumas empresas da cidade de Turim se dispuseram a oferecer oportunidade de estágio a alunos do Politecnico di Torino em troca de um projeto de melhoria. A Rostagno foi a empresa onde o autor participou deste programa. 
Na busca por melhor controle no processo gerencial e sobretudo na eficiência logisitca, optou-se pela criação de indicadores de desempenho, visto que na empresa estudada não existia nenhum. O controle era feito de forma subjetiva, muitas vezes sem critérios e pautada pelo empirismo.

\section{ANÁLISE DO MERCADO}

A Rostagno é uma movelaria de Turim especializada na fabricação de estofados: sofás, poltronas e camas. Recentemente, diversificou seu portfolio para introduzir uma linha de painéis acústicos.

Atualmente, seu faturamento é de 2 milhões de euros anuais. Seu público-alvo são clientes individuais em busca de mobiliário doméstico de alto luxo, e proprietários de hotéis, navios de cruzeiro, teatros.

O setor do mercado da divisão Casa se caracteriza por certa concentração, obtida graças à presença de barreiras à entrada: o know-how necessário para realização de produtos high-end, não é facilmente contornado por potenciais concorrentes. A crise econômica, contudo, diminuiu a atratividade do setor: a redução acentuada na capacidade de gasto do mercado europeu impôs aos operadores reduzir preços, diminuindo margens, apesar de atingir volumes de vendas capazes de cobrir custos fixos.

No segmento de luxo, os clientes têm alto poder de barganha justificada por seus gastos; exigem produtos de alto desempenho e personalização. Quanto às relações com fornecedores, a situação é mais variada: fornecedores de madeira e materiais de preenchimento, produtos com várias opções de substituição, têm limitado poder de negociação; ao contrário, fornecedores de tecidos exigem volume mínino para assinar acordos de exclusividade. Nesse caso, como a produção da Rostagno é grande, é possível atender a essa exigência resultando em uma possível fonte de vantagem competitiva em relação as empresas que não conseguem atender esse requisito.

Merece atenção a Divisão Hotel, late e Teatros cujos produtos são projetados e prototipados na Itália, mas produzidos na China. A Rostagno usa seu Knon How e o proveito do "Design in Italy" na projetação, obtendo uma vantagem competitiva em comparação aos demais, tendo bom percentual do seu faturamemto proveniente do mercado externo. 
A atuação no setor de acústica é recente. Os principais concorrentes são pequenas firmas e profissionais autônomos que, entretanto, não conseguem ter a mesma penetração de mercado que a Rostagno. Essas condições permitem à empresa entrar neste novo setor com certa facilidade, representando outra forma de diversificação.

\section{PORTFÓLIO}

Tabela 1 - Portfólio da empresa

\begin{tabular}{|c|c|c|}
\hline Divisão Casa & Divisão Hotel, late e Teatro & Divisão Acústica \\
\hline $\begin{array}{l}\text { Esta divisão inclui toda a oferta de } \\
\text { moveis Rostagno: produto de Classe A e } \\
\text { altamente personalizável, não só na cor } \\
\text { e imaginação dos tecidos, mas também } \\
\text { em formas, materiais utilizados e } \\
\text { inseridos em detalhes estruturais. } \\
\text { A empresa tem uma grande sala de } \\
\text { exposições ( } 2000 \text { m), em que exibe sua } \\
\text { coleção para o público, formado por } \\
\text { consumidores individuais e por } \\
\text { profissionais da indústria, tais como } \\
\text { arquitetos e decoradores que trabalham } \\
\text { rotineiramente com Rostagno. }\end{array}$ & $\begin{array}{l}\text { Esta divisão produz: sofás, poltronas e } \\
\text { camas, com acabamento requintado } \\
\text { com grandes possibilidades de } \\
\text { personalização. } \\
\text { A peculiaridade desta divisão deve-se } \\
\text { principalmente no design, feito } \\
\text { inteiramente nas necessidades dos } \\
\text { clientes e volumes de produtos, que são } \\
\text { elevados e, portanto, são feitas a partir } \\
\text { da terceirização na China. A clientela } \\
\text { também é diferente em relação a } \\
\text { Divisão Casa, sendo constituída } \\
\text { principalmente por proprietários de } \\
\text { hotel. }\end{array}$ & $\begin{array}{l}\text { A Divisão acústica foi recentemente } \\
\text { introduzida, um exemplo de } \\
\text { diversificação eficaz dos } \\
\text { conhecimentos especializados } \\
\text { tecnológicos realizado dentro da } \\
\text { empresa, é possível melhorar a acústica } \\
\text { de uma sala, eliminando ecos e ruídos, } \\
\text { ou isolando acusticamente o ambiente. } \\
\text { A vantagem competitiva obtida nesta } \\
\text { área é devido à sua natureza híbrida, } \\
\text { com experiência operacional e extensa } \\
\text { rede de contatos, combinado com um } \\
\text { importante know-how tecnológico que } \\
\text { garante resultados eficazes. }\end{array}$ \\
\hline
\end{tabular}

Fonte: Elaboração Própria

\section{ANÁLISE DOS DADOS}

\subsection{Ciclo produtivo}

O setor de atuação da Rostagno é caracterizado por clientes dispostos a esperar por um produto de qualidade, permitindo à empresa trabalhar exclusivamente com os pedidos dos clientes, aplicando uma política pull na gestão com fornecedores, reduzindo estoques de matéria prima e de produtos semi-acabados.

O Sistema Pull (puxado) representa um dos principais conceitos do Lean Production e consiste na produção de bens ou serviços unicamente de acordo com as necessidades do cliente (Monden, 1998).

Os processos demonstram como a organização funciona, e criam valor na perspectiva do cliente, eles são muito importantes, pois são eles que produzem o produto ou serviço que vai ao cliente, e a partir destes criam diferenciais competitivos. 
De acordo com Davenport (1994) e Moura et al (2014), o processo nada mais é que uma estrutura bem definida para a produção de bens ou serviços, ou seja, possui início, meio e fim, possuindo entradas de insumos e saídas do produto manufaturado. - 4 - Segundo Martins e Laugeni (2002), e processo pode ser determinado como o caminho percorrido por um material desde sua chegada na organização até sua transformação e saída da organização para o cliente.

Fluxograma: Processo Produtivo

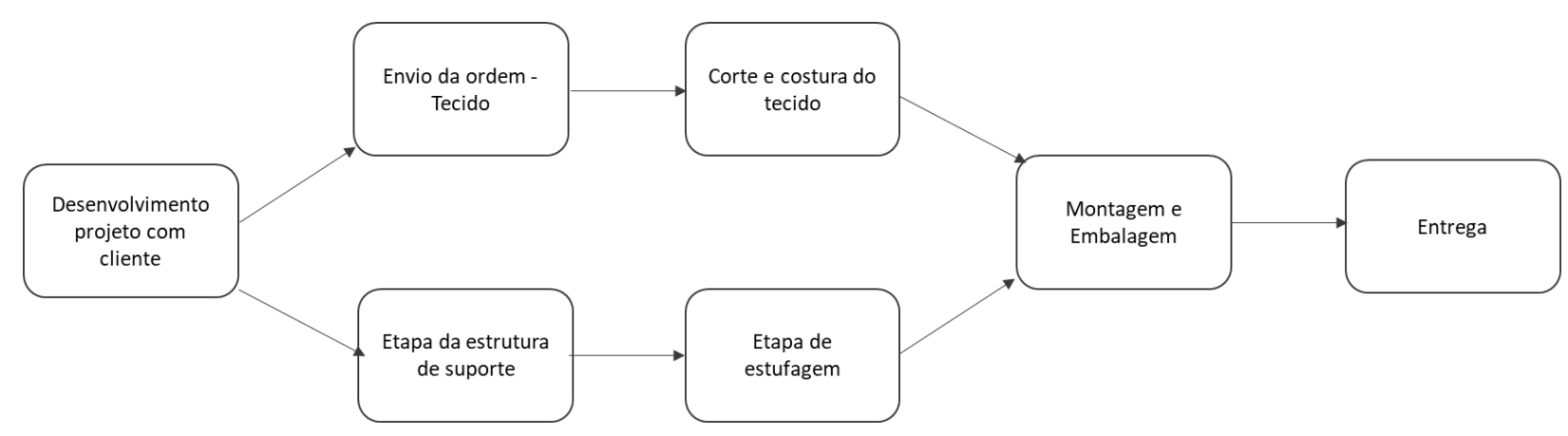

Fonte: Elaboração Própria

\subsection{Divisão casa e acústica}

O processo começa com a seleção do artigo desejado pelo cliente no catálogo, individualmente ou auxiliado por designer de interiores. Em alguns casos, é realizada implementação.

Definida a ordem, o setor administrativo é responsável por gerar o processamento de pedidos, que contém especificações do produto a ser entregue. $O$ contrato contém um código de identificação do cliente e a lista de processos a serem executados em cada um dos departamentos de produção. Paralelamente, são emitidos todos os pedidos de tecido, que serão entregues com um lead time de 10 dias.

A produção consiste em duas partes distintas: 1) realização da estrutura de suporte da peça de mobiliário. 2) produção de tecidos estofados. Estes materiais necessitam de duas operações de maquinagem independentes, o corte do pé de enchimento e a costura dos tecidos, que são, entretanto, realizados no mesmo ambiente. Todo procedimento é feito à mão, permitindo um alto grau de personalização do produto e qualidade adequada para este segmento de mercado. $O$ processo de produção dura cerca de 5 dias, seguido da entrega ao cliente. 


\subsection{Divisão Hotel, late e Teatro}

Nesta divisão, os produtos são caracterizados por grande esforço de projetação que são necessariamente divididos em volumes elevados. O modelo de negócio funciona assim: a parte do desenho e prototipagem é realizada pelos designers da Rostagno, com ajuda do arquiteto indicado pelo cliente e, após sua aprovação, inciase a produção em larga escala na China.

\section{LOGÍSTICA}

\subsection{Gestão do Estoque}

A variabilidade da demanda e do produto específico afeta profundamente a política de gestão de estoque: para maximizar os resultados econômicos, os produtos com demanda constante exigem resposta mais rápida às necessidades dos clientes devendo ser, portanto, suportadas pelo material em estoque. Os produtos caracterizados por alta personalização, ao contrário, têm característica intrínseca, como a dificuldade de prever a quantidade de material a ser armazenado em estoque: para esses itens, é mais conveniente minimizar estoques e ordenar o material necessário apenas quando receber o pedido. Segundo (MONTANHEIRO, FERNANDES, 2008) Uma eficiente gestão de estoques possibilita a organização obter melhorias significativas na sua administração, uma vez que repercute em uma melhoria na eficiência da realização da produção planejada, traz maior segurança nas tomadas de decisões, além de prevenir possíveis atrasos na entrega de pedidos

No estoque de matéria prima é mantida somente a quantidade necessária de madeira para fabricação das estruturas de suporte do móvel. Os dois tipos de madeiras são álamo e samba.

O álamo é mais utilizado na fabricação de movéis de alta qualidade, estocado em tábuas de dimensões $252 \times 187 \times 18 \mathrm{~cm}$. Este tipo de madeira é utilizado na forma de multi-camadas, garantindo solidez e leveza.

Outra alternativa é a samba. Uma madeira exótica, com coloração amarelada e branca, macia e de fácil manuseio.

No que diz respeito ao estoque de produtos semi-acabados, a situação difere, pois depende da divisão. Para a Divisão Casa, o catálogo de ofertas tem produtos 
padronizados e, geralmente, feitos pequenos ajustes para atender as necessidades do cliente. Isso contribuiu para aumentar a rapidez da tramitação do pedido. Existe a armazenagem de certos produtos semi-acabados, como as estruturas de suporte do mobiliário. Dependendo da qualidade da madeira utilizada o tempo de armazenagem é alterado.

Os produtos semi-acabados das divisões Acústica, Hotel, late e Teatro não tem nenhum tipo de estoque. As principais razões podem ser encontradas no tipo de produto fabricado, altamente personalizados, e ao fato de que a Rostagno lida exclusivamente com a fase de projeto e prototipagem, enquanto que, majoritariamente, a produção é realizada na China. Portanto, a influência destes motivos sobre o negócio do estoque semi-acabado é leve e resulta no armazenamento de materiais voltados a realização dos protótipos.

Os armazéns de estoque devem satisfazer requisitos de temperatura e umidade: quando a madeira é armazenada em ambientes de umidade elevada, tende a deteriorar-se e perder as propriedades pretendidas.

O fluxo de uma ordem e os materiais associados são geridos através de um sistema de informação interno: para cada trabalho é atribuído um código que identifica as diferentes etapas de realização. Também serve para matérias-primas e materiais comprados especificamente para a madeira previamente armazenada, identificandoos.

O turnover é fortemente influenciado pelo volume de vendas, consequentemente variavel conforme o período.

\subsection{Gestão de transporte}

A logística das matérias-primas é responsabilidade do fornecedor, sendo o preço condicionado às quantidades encomendadas e o nível de pontualidade necessário.

A Rostagno se resguarda de erros no fornecimento ou possíveis danos ao material durante o transporte através de contrato. Este permite à empresa ser capaz de realizar as atividades de controle de qualidade em um momento posterior, permitindo a seus operadores tempo adequado para verificação dos materiais recebidos. 
Para a logística de saída a gestão é por conta da Rostagno, mas limitada aos destinos italianos, onde as mercadorias são entregues diretamente ao cliente. Para produtos das divisões Acústica e Hotel, late \& Teatros seus operadores instalam os produtos.

No caso de mercadorias chinesas, a entrega é direta ao cliente.

\subsection{Rastreabilidade do produto}

Uma vez aprovado o projeto, é gerada uma folha de ordem (conforme figura 2), contendo o número de identificação do cliente, especificações do produto a ser fabricado e etapas necessárias em cada departamento: marcenaria, departamento têxtil, departamento de estofos e montagem final.

Figura 2 - Folha de ordem

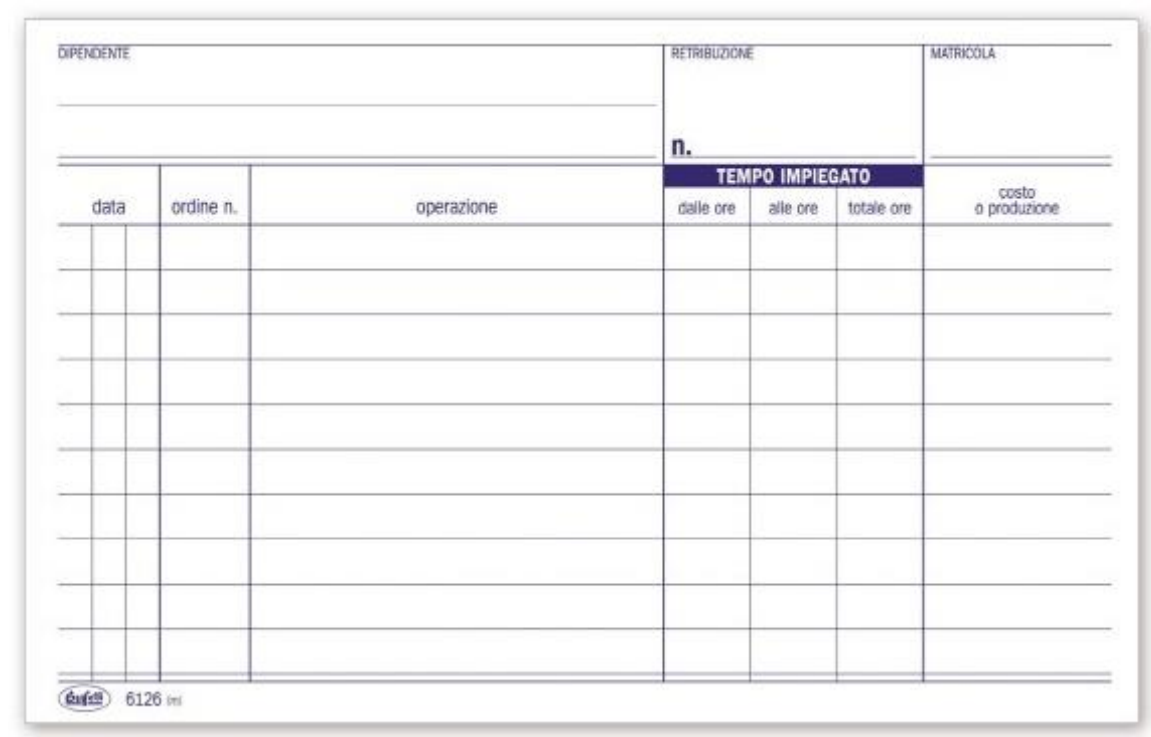

Fonte: Material utilizado na própria empresa

As informações imprescindíveis na folha de ordem são: código de identificação do fim, número de produtos acabados a serem entregues e descrição das especificações técnicas a ser utilizado nas diferentes direções para realização do produto.

Alguns exemplos da folha de ordem são as informações sobre as dimensões e tipos de madeira a ser utilizada para o departamento de carpintaria; as medidas e tipo de tecido para o departamento de matérias têxteis; a descrição do corte a ser feito e o grau de não-deformabilidade para o departamento de preenchimento; procedimento de montagem. 


\subsubsection{Madeira e estofados}

Neste departamento são realizadas as primeiras operações. No momento da construção da armação de madeira gera a folha de ordem de trabalho, que dá início ao rastreamento do produto ao longo das etapas de produção. A informação que está contida nas fases preliminares são os códigos do cliente e a ordem de identificação: Estes dados, em conjunto, identificam exclusivamente uma ordem. Desde o início, cada operador reporta o tempo de processamento utilizado no produto, a fim de obter dados que ajudarão a compreender o nível de eficiência da produção.

\subsubsection{Tecido}

Os tecidos são armazenados em grupos, com amostras diferentes, identificadas por um código, válido tanto para a empresa de fornecimento do tecido quanto para a Rostagno. Na folha de ordem é relatado o código do tecido a ser utilizado para a realização do serviço. Uma vez que o departamento têxtil termina o processamento do produto, o código do tecido é eliminado e o produto só protege os códigos necessários para a sua identificação: do cliente e da ordem.

\subsubsection{Produto acabado}

Realizadas a estrutura e revestimentos, o departamento de montagem emite ordem de entrega do projeto, identificados pelos códigos de clientes e de pedidos. Este documento consiste em uma lista de produtos semi-acabados que tenham sido concluídos em departamentos anteriores e que devem ser reunidos para completar o processo.

Neste ponto, os códigos do cliente e do pedido são relatados tanto no projeto como no semi-acabado, de modo a facilitar a montagem do produto final. Aos produtos acabados são então atribuídos endereço de destino, nome do cliente final e informações necessárias para a entrega do produto.

\section{KEY PERFORMANCE INDICATOR}

Os KPIS devem ser de fácil compreensão, pois conduzem a ações positivas nas empresas criando um sentimento de empowerment. 
Analisando a logística da empresa, foram criados alguns indicadores (mostrado nas tabelas 2 e 3) para adequação ao monitoramento da performance e individualização de eventuais questões críticas do processo.

\begin{tabular}{|c|c|c|}
\hline Símbolo & Fórmula e Descrição & Leitura \\
\hline \multirow{2}{*}{ DDS } & Due Date Supplier Index $=\frac{\# \text { Fornecimento na data }}{\# \text { Total fornecimento }}$ & \multirow{2}{*}{$\begin{array}{l}\text { Preferência aos } \\
\text { fornecedores que } \\
\text { maximiza o } \\
\text { indicador }\end{array}$} \\
\hline & $\begin{array}{l}\text { Índice de avaliação da confiabilidade dos fornecedores de materia prima para } \\
\qquad \text { Rostagno Srl }\end{array}$ & \\
\hline \multirow{2}{*}{ DDD } & Due Date Delivery Index $=\frac{\# \text { Entrega do Produto na data }}{\# \text { Total entrega produto }}$ & \multirow{2}{*}{$\begin{array}{l}\text { Preferência aos } \\
\text { fornecedores que } \\
\text { maximiza o } \\
\text { indicador }\end{array}$} \\
\hline & $\begin{array}{l}\text { Índice de avaliação da confiabilidade da entrega ao cliente } \\
\text { (De acordo com a data prevista no momento da expedição) }\end{array}$ & \\
\hline \multirow{2}{*}{ DDPS } & Due Date Percentage Supplier Index $=\frac{\# \text { Dias de atraso total }}{\# \text { dias total de expedição }} \%$ & \multirow{2}{*}{$\begin{array}{l}\text { Preferência aos } \\
\text { fornecedores que } \\
\text { minimiza o } \\
\text { indicador }\end{array}$} \\
\hline & $\begin{array}{l}\text { Índice de avaliação da confiabilidade da entrega dos fornecedores de materia prima } \\
\text { para Rostagno }\end{array}$ & \\
\hline \multirow{2}{*}{ DDPD } & Due Date Delivery Index $=\frac{\# \text { entrega na data }}{\# \text { total de entrega }} \%$ & \multirow{2}{*}{$\begin{array}{l}\text { Objetivo da } \\
\text { Rostagno deve ser } \\
\text { a minimizar este } \\
\text { indicador }\end{array}$} \\
\hline & $\begin{array}{l}\text { Índice de avaliação da confiabilidade da entrega ao cliente, levando em conta a } \\
\text { duração do atraso } \\
\text { (Avaliadas por referência à data prevista no momento da expedição) }\end{array}$ & \\
\hline \multirow{2}{*}{ DI } & Defectiveness Index $=\frac{\# \text { material recebido não conformidade }}{\# \text { material recebido }}$ & \multirow{2}{*}{$\begin{array}{l}\text { Preferência aos } \\
\text { fornecedores que } \\
\text { minimiza o } \\
\text { indicador }\end{array}$} \\
\hline & $\begin{array}{l}\text { Índice DI avalia a confiabilidade do fornecedor quanto a qualidade do material } \\
\text { entregue, uma vez verificado pelos funcionários da Rostagno. }\end{array}$ & \\
\hline
\end{tabular}


Tabela 3 -

\begin{tabular}{|c|c|c|}
\hline \multirow{2}{*}{ IRMP } & Index of raw material turnover $=\frac{\text { Materia Prima retirada durante } T}{\text { Estoque médio durante } T}$ & \multirow{2}{*}{$\begin{array}{c}\text { Objetivo da } \\
\text { Rostagno deve ser } \\
\text { a maximizar este } \\
\text { indicador }\end{array}$} \\
\hline & $\begin{array}{l}\text { O índice IRMP mede a taxa de rotatividade do estoque de matérias-primas que } \\
\text { quantifica o risco de deterioração e / ou obsolescência dos produtos armazenados. } \\
\text { Aumentar a duração média de armazenamento reduz o IRMP. }\end{array}$ & \\
\hline \multirow[b]{2}{*}{ IRWIP } & $I R W I P=\frac{\text { Semi acabado retirado durante } T}{\text { Estogue médio durante } T}$ & \multirow{2}{*}{$\begin{array}{l}\text { Objetivo da } \\
\text { Rostagno deve ser } \\
\text { a maximizar este } \\
\text { indicador }\end{array}$} \\
\hline & $\begin{array}{l}\text { O índice IRWIP mede a taxa de rotatividade do estoque de semi acabados que } \\
\text { quantifica o risco de deterioração e / ou obsolescência dos produtos armazenados. } \\
\text { Aumentar a duração média de armazenamento reduz o IRWIP. }\end{array}$ & \\
\hline
\end{tabular}

\section{ANÁLISE DA CRITICIDADE}

\subsection{Recebimento do pedido}

Devido a alta customização, um único pedido pode exigir um elevado número de ações preparatórias, com consequentes custos relacionados à gestão prolongada do projeto. Isto ocasiona atrasos na entrega final.

Além disso, dada à limitada disponibilidade de recursos e dificuldade em redução do preço, o número de orçamentos ao mesmo cliente é limitado.

\subsection{Fornecimento}

Dada à dificuldade de previsão precisa, a demanda e a elevada personalização exigida pelos clientes, é difícil programar a aquisição de matérias-primas, resultando em um adiamento da entrega do produto quando o material presente em estoque é insuficiente para o cumprimento da ordem.

No que diz respeito à divisão, Hotel, late e Teatros, é possível que as especificações técnicas enviadas para o produtor chinês não sejam perfeitamente implementadas, resultando na necessidade de enviar pessoal especializado.

\subsection{Produção}

O material mais crítico é definitivamente o tecido, pela grande variedade de modelos. Além disso, dado ao alto custo, requer um tratamento cuidadoso durante o 
processo. Enquanto matérias-primas, como madeira e estofamento, podem ser semiacabadas e armazenadas antes do início do projeto, o mesmo não acontece para tecidos, customizados especificamente no momento, quando são cortados e costurados. Além disso, seu fornecimento exige uma análise cuidadosa do mercado de móveis de luxo, porque alguns fabricantes de tecidos os fornecem somente sob contratos de exclusividade, exigindo determinadas metas de vendas.

\subsection{Projeto e prototipagem}

Durante o planejamento e realização do protótipo, podem existir dificuldades em corresponder adequadamente às necessidades do cliente. Quando isso ocorre na fase de projetação, implica atrasos e possível dano na imagem; já quando ocorre na realização do protótipo é um problema mais sério, uma vez que equivale a desperdício de recursos humanos e materiais, resultando na necessidade de repetir o processo de criação e consequente geração do protótipo.

\subsection{Entrega}

As entregas em território italiano são realizadas diretamente pela Rostagno e não há problemas. Entretanto, em relação as de responsabilidade do fabricante chinês, a Rostagno não dispõe da capacidade de controle expondo-se a qualquer problema na entrega.

\section{PROPOSTAS DE MELHORIAS}

Uma vez identificados os principais problemas da logística, procedeu-se a apresentar propostas para melhorias destinadas a eliminar ou reduzir seu impacto.

\subsection{Recebimento do pedido}

Os problemas críticos nesta fase são principalmente relacionados com o fato da alta personalização do produto requerer muitas avaliações iniciais, aumentando o tempo necessário para o recebimento da ordem de serviço.

Isso impossibilita executar as ordens de matérias-primas antes do orçamento aceito, aumentando o tempo de resposta às demandas dos clientes. 
Uma solução possível, pelo menos para produtos que não exigem criação de protótipos, seria tornar mais vinculativos os orçamentos, de modo a realizar préencomendas de matérias-primas quando gerado o orçamento. A ideia é criar uma multa de $10 \%$ em caso de desistência.

Esta solução seria aplicada a partir do segundo orçamento; a medida teria o efeito de desencorajar a procura de clientes não dispostos a pagar os preços propostos pela Rostagno que, após longa negociação, desistem da compra e geram custos para a empresa sem retorno financeiro.

\subsection{Fornecimento}

Quanto ao relacionamento com seus fornecedores, no momento a Rostagno está exposta tanto em termos de fornecedores de matérias-primas, cujos serviços não são regulados por contrato através de KPI, tanto ao nível dos recrutadores de mãode-obra chinesa, cujos erros ou atrasos podem causar danos para sua imagem.

Propõe-se, para maior segurança nas relações contratuais com os fornecedores de matérias-primas, utilizar os KPIs propostos anteriormente (tabela $2 \mathrm{e}$ 3), formalizar seu compromisso de garantir resultados de desempenho. A falta de cumprimento da meta de desempenho sujeita à multa de $5 \%$ do volume movimentado.

Quanto aos trabalhadores chineses, que também se encarregam da entrega dos produtos ao cliente final, propõe-se a inclusão de penalidades para erros em andamento envolvendo atrasos ou insatisfação do cliente. Neste caso, o dano a imagem depende da extensão do pedido, podendo estar compreendida num intervalo desde $5 \%$ até $50 \%$ do valor monetário do último pedido.

\subsection{Projeto e prototipagem}

O processo de prototipagem é atualmente utilizado para aceitação do produto pelo cliente da divisão Hotel, late e Teatro e como benchmark a ser enviado para o fabricante chinês como suporte à produção.

Segundo Pearrow (2000) um protótipo é um modelo semi-funcional do produto final. Usar uma versão parcialmente finalizada, é uma maneira comum de realizar testes de usabilidade já nas fases iniciais do ciclo de vida do projeto. 
Rubin (1994) afirma que ao desenvolver um protótipo não se faz necessário representar toda a funcionalidade do produto. Pelo contrário, somente deve ser representada a funcionalidade que atenda aos objetivos do teste ou da avaliação.

Este método de gestão tem, contudo, risco de, em caso de rejeição, a reconstrução do protótipo, com os custos envolvidos em termos de tempo, trabalho e materiais.

Por conseguinte, propõe-se criar um protótipo não-físico através de softwares especializados e submeter este último à aceitação do cliente. Isto reduziria tempo e custos de implementação, bem como flexibilizaria a mudanças.

\subsection{Realocações da produção}

As encomendas chinesas envolvem encargos em termos de custo para monitoramento do pedido, a nível de conformidade e qualidade, não devendo subestimar o tempo de espera alta de aquisição (30-40 dias) que reduz a capacidade de resposta em atender as solicitações dos clientes.

Uma solução possível seria os fornecedores do leste europeu. Neste cenário, seria mais fácil e mais barato enviar seus funcionários em caso de problemas na linha de produção, aumentar a frequência dos controles de qualidade definidos por contrato. A abordagem dos locais de produção teria o benefício de reduzir significativamente $o$ lead time, oferecendo uma alternativa para demandas com o tempo de espera reduzido.

O trade-off apresentado aumenta os custos de produção, vez que o ainda baixo custo por hora de trabalho no leste europeu, ainda é maior do que o chinês, e uma cadeia de suprimentos que é mais fácil de controlar, mais reativa e garante maior qualidade ao nível do produto.

Segundo a pesquisa, Polônia (distrito de Zagłębie) e Romênia (distrito de Arges) foram apontadas como alternativas à produção chinesa.São zonas especializadas no trabalho com a madeira e tecidos, tendo um grupo elevado de empresas italianas que já deslocaram a própria produção. O profissionalismo já presente nestas áreas garante qualidade e capacidade produtiva.

Comparando as alternativas, realizou-se uma avaliação econômica da viabilidade, com a situação atual da produção na China. Os fatores considerados: custos do trabalho e transporte (conforme tabela 5, 6 e 7). Embora deva ser salientado 
que os resultados quantitativos obtidos são integrados com as considerações qualitativas listados anteriormente.

Foram utilizadas as seguintes informações (Tabela 4):

Tabela 4 - Dados para produção

\begin{tabular}{|l|r|}
\hline Operários externos & 20 \\
Serviços realizados anualmente em outsourcing & 11 \\
Horas de trabalho diário & $8 \mathrm{~h}$ \\
Duração média dos serviços & 20 dias \\
Quantidade caminhão/cointainer para o transporte & 1 \\
Faturamento Rostagno & $2.000 .000 €$ \\
\hline
\end{tabular}

Fonte: Elaboração própria a partir de dados fornecidos pela empresa

Tabela 5 - Custo total anual em cada país

\begin{tabular}{|c|c|c|c|c|}
\hline $\begin{array}{l}\text { Local da } \\
\text { Produção }\end{array}$ & $\begin{array}{l}\text { Custo Total Anual } \\
\text { Outsourcing }\end{array}$ & \multicolumn{2}{|c|}{ Confronto com a Situação Atual } & $\begin{array}{l}\text { Incidência } \\
\text { Outsourcing sobre } \\
\text { Faturamento }\end{array}$ \\
\hline China & $62.788 €$ & - & - & $3,14 \%$ \\
\hline Romênia & $166.870 €$ & $104.082 €$ & $165 \%$ & $8,34 \%$ \\
\hline Polónia & $271.920 €$ & $209.132 €$ & $308 \%$ & $13,60 \%$ \\
\hline
\end{tabular}

Fonte: Elaboração própria a partir de dados fornecidos pela empresa

Tabela 6 - Custo de transporte

\begin{tabular}{|c|c|c|c|}
\hline Local da Produção & $\begin{array}{c}\text { Custo Unitário do } \\
\text { Transporte }\end{array}$ & $\begin{array}{l}\text { Tempo Médio do } \\
\text { Transporte }\end{array}$ & Custo Anual do Transporte \\
\hline China & $1644 € /$ container & $30-35$ Dias & $18.084 € / a$ \\
\hline Romênia & $450 € /$ caminhão & $24-48$ Horas & $4.950 € / a$ \\
\hline Polónia & $400 €$ /caminhão & $24-48$ Horas & $4.400 € / a$ \\
\hline
\end{tabular}

Fonte: Elaboração própria a partir de dados fornecidos pela empresa

Tabela 7 - Custo da mão de obra

\begin{tabular}{|ccc|}
\hline Local da Produção & Custo Hora da Mão de obra & Custo Anual Mão de obra \\
\hline China & 1,27 & $44.704 € / a$ \\
\hline Romênia & $4,60 €$ & $161.920 € / a$ \\
\hline Polónia & $7,60 €$ & $267.520 € / a$ \\
\hline
\end{tabular}

A escolha sugere cautela na adoção de uma estratégia. Em relação as opções de fabricação, a Romênia prova ser a melhor alternativa como uma possível substituição a produção chinesa, garantindo um perfeito equilíbrio entre a capacidade 
de resposta e de custos de trabalho. Os indicadores contribuíram como uma ferramenta de gestão para tomada de decisão.

\section{CONSIDERAÇÕES FINAIS}

O presente trabalho constituiu na aplicação de indicadores de desempenho no contexto logístico de uma empresa de movelaria. Através de comparação entre dados dos fornecedores poloneses e romenos, foi sugerido uma alternativa à produção chinesa para aumentar a capacidade de resposta da Rostagno nas demandas que exigem entrega mais rápida.

Efetuar a gestão por indicadores de desempenho é um diferencial, que traz vantagem competitiva para as empresas, e um fator determinante para a sobrevivência e crescimento no cenário em que a concorrência está cada vez maior, principalmente de mercados que antigamente não era ameaças, mas se tornaram por conta dos custos locais, e os clientes mais exigentes, pois permite que as estratégias sejam implementadas e constantemente verificadas.

Por meio dessa análise, conclui-se que a Rostagno está vulnerável em alguns aspectos e, por isso, foram apresentadas propostas de melhorias para cada um dos itens em questão.

A melhor alternativa para a produção chinesa são os fornecedores romenos, mais especificamente da região de Arges, pois seu tempo de entrega não supera 48 horas, com incidência de 8,34\% sobre o faturamento, diferentemente da Polônia, com 13,60\%. Para a tomada de decisão recomenda-se a utilização dos indicadores criados, como forma de controle e mensuração das entregas dos fornecedores.

Os indicadores da empresa precisam ser ajustados conforme sua utilização, pois foram os primeiros KPls propostos, fazendo adequações mais pertinentes conforme as próximas experiências e os feedbacks dos envolvidos. Entretanto estes possibilitam uma gestão de controle mais eficiente e assertiva, baseada em índices quantitativos, garantindo maior qualidade e ganho na imagem perante ao mercado.

De maneira geral, a implementação dos KPls teve uma boa aceitação por parte dos gestores da empresa, que julgaram o trabalho viável, e reconheceram sua importância. 


\section{REFERÊNCIAS}

ANSOFF, H. I. Corporate strategy: an analytic approach to business policy for growth and expansion. New York: McGraw-Hill, 1965.

BALLOU, Ronald. Business logistics management. Englewood Cliffs: Prentice Hall, 1998.

BARBROW, S.; HARTLINE, M. Process mapping as organizational assessment in academic Librarie. Performance Measurement and Metrics, 2015. https://doi.org/10.1108/PMM-11-2014-0040

BEULKE, Rolando; BERTÓ, Dalvio José. Estrutura e análise de custos. 1. ed. São Paulo: Saraiva, 2001.

CAROL TAYLOR FITZ-GIBBON. Performance indicators, BERA Dialogues Hardcover, 1990.

CANHADAS, L. S.; Implantação do balanced scorecard por uma operadora logística e sua integração com a empresa contratante. 2010. 67f. Trabalho de Conclusão de Curso (Graduação em Engenharia de Produção Mecânica) - Universidade de São Paulo, São Carlos, 2010.

CHIAVENATO, I.; SAPIRO, A. Planejamento estratégico. Rio de Janeiro, RJ: Elsevier, 2009. p. 30- 1, 252-8.

DAVENPORT, Thomas H. 1994. Reengenharia de processos: como inovar na empresa através da tecnologia da informação. Rio de Janeiro, RJ: Campus. ISBN 85-7001-874-6

DORNIER, P. P. et al. Logística e operações globais: textos e casos. 1. ed. 10 reimpr .São Paulo: Atlas, 2012.

DUARTE, F. Táticas bope de redução de custos logísticos. Mundo logística. São Paulo, v. 9, n. 54, p. 64-67, set/out. 2016.

FUNDAÇÃO NACIONAL DA QUALIDADE-FNQ. Critérios de excelência. São Paulo: 2002.

GAJ, Luis. O estrategista: do pensamento à ação estratégica na organização. São Paulo: Editora Makron Books, 2002.

GIBBON, Carol Taylor Fitz. Performance indicators. BERA Dialogues,1990

JURAN, J.; GRYNA, F. Quality control handbook. Nova York: McGraw-Hill, 1998

KOTLER, Philip. Administração de marketing: análise, planejamento, implementação e controle. 2. ed. São Paulo: Editora Atlas, 1992.

MITCHELL, G. Problems and fundamentals of sustainable development indicators, 2004.

MONDEN, Y. Toyota production system: an integrated approach to just-intime. Edição 3rd, Engineering \& Management Press, a division of the Institute of Industrial Engineers, Georgia, United States of America, 1998. 
MONTANHEIRO, W. J.; FERNANDES, L. A. Gestão de estoques de materiais em uma confecção. In: SIMPÓSIO DE EXCELÊNCIA EM GESTÃO E TECNOLOGIA, 5., 2008, Resende. [Anais...]. Resende, Associação Educacional Dom Bosco, 2008.

MOREIRA, D. A. Administração da produção e operações. 2. ed. São Paulo: Cengage Learning, 2008

MOURA et al. Análise e mapeamento de processos em uma empresa de engenharia prestadora de serviço ao setor ferroviário. Bauru - SP: Unesp, XXIII SIMPEP, 23., 2014. [Anais...] Artigo 404, [online]. Disponível em: http://www.simpep.feb.unesp.br/anais simpep.php?e=9. Acesso em: 25 out 2015.

NOVAES, A. Logística e gerenciamento da cadeia de distribuição: estratégia, operação e avaliação. Rio de Janeiro: Campus, 2001, 409 p.

OLIVEIRA, Djalma de Pinho Rebouças.Planejamento estratégico: conceito, metodologia prática. 25. ed. São Paulo: Atlas, 2008

PARASURAMAN, A. Marketing research. 2. ed. Addison Wesley Publishing Company, 1991.

PARMENTER, D. Key Performance Indicators (KPI): Developing, Implementing, and Using Winning KPIs. Hoboken: Wiley, 2007.

PEARROW, M. Web site usability handbook. Massachusetts: Charles River Media, 2000.

PIRES, S. R. I. Gestão da cadeia de suprimentos e o modelo de consórcio modular. Revista de Administração, São Paulo, 1998

PORTER, M. E. (1985). Competitive advantage: creating and sustaining superior performance. New York: Free Press, Collier Macmillan.

RUBIN, J. Handbook of Usability Testing: how to plan, design and conduct effective tests. New York: John Wiley \& Sons, 1994.

SLACK, Nigel; JOHNSTON, Robert; CHAMBERS, Stuart. Administração da produção. 3. ed. São Paulo: Atlas, 2009.

TOFOLI, I. Administração de recursos materiais e patrimoniais: uma abordagem logística. 4. ed. São Paulo: Atlas, 2007.

VENDRAME, F. C. Administração financeira empresarial: uma tratativa prática. Lins, Arte Brasil, 2008.

ZELTZER, R. Indicadores de desempenho coleta e análise de dados, estabelecer indicadores e promover melhoria contínua. NewsLab. Edição 71, 2005.

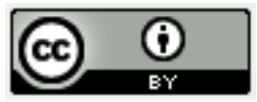

Artigo recebido em: 06/12/2018 e aceito para publicação em: 01/12/2019

DOI: http://dx.doi.org/10.14488/1676-1901.v19i4.3496 